\title{
Knowledge Level and Self-Reported Attitudes of Food Handlers: Case Study of a University Campus
}

\author{
Kamila Soares' ${ }^{1}$, Irene Oliveira ${ }^{2}$, Alexandra Esteves ${ }^{1}$, Maria C. Fontes ${ }^{1}$, Cristina Saraiva ${ }^{{ }^{*}}$ \\ ${ }^{1}$ School of Agrarian and Veterinary Sciences, DCV, CECAV, Centro de Ciência Animal e Veterinária, Universidade de Trás-os-Montes e \\ Alto Douro, Vila Real, Portugal \\ ${ }^{2}$ School of Science and Technology, DM, CITAB, Centre for the Research and Technology of Agro-Environmental and Biological \\ Sciences, Universidade de Trás-os-Montes e Alto Douro, Vila Real, Portugal \\ Email: *crisarai@utad.pt
}

How to cite this paper: Soares, K., Oliveira, I., Esteves, A., Fontes, M.C. and Saraiva, C. (2016) Knowledge Level and Self-Reported Attitudes of Food Handlers: Case Study of a University Campus. Health, 8, 1383-1396. http://dx.doi.org/10.4236/health.2016.813139

Received: May 4, 2016

Accepted: October 18, 2016

Published: October 21, 2016

Copyright $\odot 2016$ by authors and Scientific Research Publishing Inc. This work is licensed under the Creative Commons Attribution International License (CC BY 4.0).

http://creativecommons.org/licenses/by/4.0/

\begin{abstract}
This study was performed conducting surveys to assess the Knowledge Level (KL) and Self-Reported Attitudes (SRA) of Food Handlers (FH) in order to evaluate their food safety perception. Food handlers working in 5 cafes and 6 canteens in a university campus responded to a questionnaire about food hygiene. The knowledge level about food hygiene was obtained by answering five question groups $(G)$ : Agents involved in food borne diseases (G1), Food handling hygiene (G2), Cross contamination (G3), Heat treatment/cooling techniques (G4), Reduced temperatures (G5). The SRA level was obtained through seven questions with multiple choice options on behaviors of health and safety applied to the work routine, which were considered as percentage of hits. The hygiene's knowledge average was 75\%, ranging from $63.3 \%$ (G4) to $94.5 \%$ (G3). Significant associations between establishment type and G1 ( $p=$ $0.027)$, professional experience and G5 $(p=0.020)$, training and G5 $(p=0.037)$ were found. Food handlers knowledge did not have effect in FH attitude $(p=0.371)$. From $25 \mathrm{FH}$ (46.0\%) who had high KL, 17 had reported incorrect attitudes. The level of hits is, in general, more than $75 \%$, except for matters relating to the use of different cutting tables (44.4\%) and knives (51.9\%). Significant differences of values and odds for handlers' knowledge were observed between cafes' and canteens' FH. No difference $(p>0.05)$ was observed in FH SRA scores according to the type of establishment. The results reveal a reduced application of knowledge acquired by food handlers, evidenced by the low level of attitudes considered correct. This clearly justifies the implementation of additional measures, including on job training as part of an effective strategy to control establishment's food safety.
\end{abstract}




\section{Keywords}

Food Handlers, Knowledge, Self-Reported Attitudes, Training, Food Safety

\section{Introduction}

Food safety is one of the consumer's major concerns, fearing what is not safe for their health [1]. Nowadays, food establishments in Europe must comply with strict food legislation known as the "hygiene package" which requires them to have a food safety system in place based on HACCP principles, by establishing a set of measures and imposing hygiene rules for products [2] [3].

Food hygiene implies the application a set of measures and conditions to control hazards to ensure that food is safe and suitable for human consumption. Besides those important regulations, the occurrence of outbreaks of Food Borne Diseases (FBD) continues to be prevalent and constitute an essential health problem in the World. In 2013, a total of 5196 food-borne outbreaks in EU, including water-borne outbreaks, were reported by the European Food Safety Authority (EFSA) and the European Centre for Disease Prevention and Control (ECDC) [4]. The occurrence of outbreaks of FBD's is often associated with a variety of pathogens, namely Salmonella sp., Campylobacter spp., E. coli O157: H7, Listeria monocytogenes, Bacillus cereus, C. perfringens and $S$. aureus [5].

Food contamination can appear during all steps of food chain and corresponds to the occurrence of a hazard such as any biological or chemical agent, foreign matter or other substance not intentionally added to food which may compromise food safety [6].

Canteens and cafes are often associated with outbreaks of food borne illness and Food Handlers (FH) practices have a key role in ensuring food safety throughout the chain of food production, processing, packaging or distribution [7].

The main factors that are responsible for generating outbreaks of food contamination are improper handling, inadequate heat treatment, the use of contaminated unprocessed ingredients, incorrect application of the time/temperature relation in food storage and infected FH. These factors are based mainly on low knowledge and inadequate hygiene practices among $\mathrm{FH}$ and demonstrate the risk factor represented by humans in the context of food safety [8] [9].

The importance of FH training is provided by the Regulation (EC) No. 852/2004, which stresses that those who are responsible should receive and promote adequate training in the application of HACCP principles and respect all the requirements of national law [2].

The effectiveness of training programs depends on changing inappropriate behavior by handlers through time. To make it happen, training programs must involve practical instruction besides theoretical lessons to become more effective. Several studies in school cafeterias [10]-[16], and also in restaurants from various countries [7] [17] [18] [19] reported the importance of HACCP implementation plans and prerequisites sys- 
tems improved food safety of the meals provided [20]. Authorities have carried out official controls to verify compliance by the operators of the food safety program implementation. Those are based on the HACCP principles and should guide food business operators for minimum hygiene requirements which must be introduced in their companies [2].

In summary, work-based surveys conducted to $\mathrm{FH}$ are of great importance to discover the weak points in terms of knowledge, and combining a follow-up of theoretical courses and practical advances, to increase the level of good hygiene practices and manufacturing by those intervening in the food chain to ensure food safety to consumers.

The objective of this study was to evaluate the socio-demographic characteristics, the level of knowledge and attitudes of food handlers, with the aim of seeking relations between theory and practice, in this case, verify that the handlers have the necessary knowledge about good hygiene practices and manufacturing, and the same knowledge is reflected in attitudes, and socio-demographic characteristics influence the KL and SRA. The information obtained can facilitate those running the establishments, to choose the most appropriate type of training and it will be sufficient to correct improper behavior and attitudes.

\section{Methods}

\subsection{Participating Businesses}

This study was based on a survey of food handlers' working in 6 canteens and 5 cafes located in a university campus of Portugal.

Canteens layouts have a physical separation between distinct areas: layoff; preparation of products; processing area, pastry area; cup; plating and distribution, and selling on-line. Instead, cafes are smaller and do not have specific areas physically separated.

When the study was conducted, all establishments had implemented a food safety system based on HACCP system according to the Portuguese legislation [21]. From 60 FH presented in those establishments, 54 (90.0\%) responded to the questionnaire.

\subsection{Structure of the Questionnaire about the Level of Knowledge and Self-Reported Attitudes}

The questionnaire was adapted from Santos [22] and is described in Soares [16], consisting in XIII questions groups, with questions concerning demographic aspects (age, gender, level of education, duration of employment in the food area and aspects related to vocational training), personal hygiene, handlers clothing and the basic knowledge about: food borne illnesses, vehicles/agents involved in the transmission of food borne illness, food handling hygiene, cross contamination, thermal treatments and cooling techniques, use of low temperatures, the HACCP system and the SRA.

SRA measures correspond to questions with multiple answers about practical routine situations such as hand-washing and control temperatures that require to the FH respondents to choose the most correct answer correspond to the most adequate attitude.

Each question about knowledge had three choices of answers: yes, no and do not 
know/no answer, the latter was included to reduce the probability of random responses being considered correct.

\subsection{Statistical Analysis}

Data were analyzed using IBM SPSS ${ }^{\oplus}$ Statistics version 22 . The KL of FH was established considering the percentage of correct responses for questions groups of issues.

Chi-square nonparametric test for homogeneity was used regarding associations of the KL and SRA with demographic aspects, and in some demographic attributes ordinal categories were recorded into fewer to validate chi-square test assumptions.

A global KL score was calculated and a binary result was considered with the median (80\%) as the cut-point reported in Abdul-Mutalib et al. [17]. Aglobal SRA was also expressed as percentages of attitudes considered correct and was coded as performed by Lilian et al. [23]: incorrect attitude as $0(\leq 80 \%)$ and correct attitude as $1(>80)$. The influence of global KL in SRA was also studied.

Multiple logistic regression (MLR) analysis were performed by taking into consideration factors where significant differences were obtained by Chi-square tests evaluated in each Group (G) of KL and Questions (Q) about SRA of FH, and global KL, yielding regression coefficients, odds ratios (OR) and $p$-values.

Stepwise variable selection method was used for the selection of variables to be entered in the models. The analyses were conducted using age, gender, age, professional experience, training and type of establishment, as independent variables. Models were evaluated for binary response variables in each Group (G) of KL and Questions (Q) about SRA of FH, and global KL.

\section{Results}

\subsection{Demographic Characteristics of FH}

Forty participants were female and 14 male, and $87 \%$ have more or equal 36 years. Relating to the education level, from our respondents $79.6 \%$ have 9 and 12 years of schooling, and $20.4 \%$ have less or equal the 6th grade.

Regarding professional experience, $9.3 \%$ of participants had between 2 and 5 years; $20.4 \%$ had between 6 and 10 years, 48.1 .\% from 11 to 20 years of experience in the food area and $22.2 \%$ participants more than 20 years in the same workplace.

According to the work activity, $83.3 \%$ perform multipurpose functions related to food handling and only $16.7 \%$ perform specific functions, related to payment and storage.

Forty-eight FM (89.0\%) say they have training in the food sector, including food hygiene, HACCP methodology, and health and safety at work were cited training topics. However, it should be noted that in the same survey, when faced with the question: "What is HACCP", only $55.6 \%$ of FH responded correctly to its definition.

In addition, when asked about their interest in new training in the food area, 85.2\% of respondents said yes, and only $14.8 \%$ remained uninterested. 
Food handlers were subjected to questions about personal health and hygiene, where most of the handlers (51.4\%) reported that when they are sick are missing or are on sick leave, and the rest going to work (48.6\%) make the mistake of not informing responsible about their health status, not complying with the rules of the Codex Alimentarius [24].

\subsection{Statement of KL and SRA Level}

Participants had an overall knowledge greater than $60.0 \%$ in each group of questions, and the total $\mathrm{KL}$ average was $75 \%$ (Table 1). Concerning a different question (results not shown) about their pathogenic microorganism knowledge, besides cited five microorganisms: Salmonella sp., Staphylococcus aureus, Listeria monocytogenes, Clostridium perfringens and Clostridium botulinum, 96.3\% of FH only recognized Salmonella sp. and none had recognized other pathogens.

Table 2 presents the results of issues related to SRA. This group is to accentuate that all participants answered that they do not use thermometer to check the temperature of food after cooking ignoring the recommendation of its use.

\subsection{The Relationship of KL and SRA and Socio-Demographics Characteristics}

The association between socio-demographic characteristics of $\mathrm{FH}$ with the average for questions in each group and with the average of total knowledge about food safety and hygiene are presented in Table 3.

According to the type of establishment significant differences were observed in G1 of knowledge's questions and for level of total knowledge, where 55\% of $\mathrm{FH}$ from cafes responded correctly. On the contrary, only $25 \% \mathrm{FH}$ from canteens responded correctly $\left(\chi^{2}=4.913, \mathrm{df}=1, p=0.027\right)$. FH from cafes presented $72 \%$ of high total $\mathrm{KL}$, compared to those working in canteens where only $41 \%$ presented high total $\mathrm{KL}\left(\chi^{2}=4.488, \mathrm{df}=\right.$ $1, p=0.034)$.

Regarding knowledge about low temperatures, significant differences $\left(\chi^{2}=5.373\right.$, df $=1, p=0.020$ ) were observed in relation to professional experience, with respondents with more years of experience answered less correctly (75\%). Significant differences $\left(\chi^{2}\right.$ $=6.592, \mathrm{df}=1, p=0.037)$ were also found in relation to training in food safety, where who had at most 2 years of training responded more accurately (80\%).

In Table 4, the MLR with significant results are presented. In model 1, for G1 binary KL response variable the type of establishment was significant (Wald $\chi^{2}=4.686, p=$ 0.030 ), and the odds of higher KL related to the vehicles and transmitting agents of FBD's are about 3.75 times greater for FH from cafes than canteens.

In model 2, within FH that had some training (49) about knowledge of reduced temperatures (G5) two effects were significant, profession experience (Wald $\chi^{2}=5.325, p=$ 0.021 ) and time training (Wald $\chi^{2}=4.274, p=0.039$ ).

The odds that a FH with more experience has higher $\mathrm{KL}(>80 \%)$ is 5.46 times greater than the odds of a FH with low experience. On the other hand FH with less than 2 two years of training had a chance 4.43 times greater for correct answers.

Analyzing the time of formation of FH and your knowledge, we found that 8 in 14 (57\%) 
Table 1. Assessment (\%) of food safety knowledge of food handlers by questions and groups of questions in the one University of Portugal $(\mathrm{n}=54)$.

\section{Statements}

\section{Group 1: Vehicles/Agents involved in the transmission of Foodborne disease}

1. Eggs can contain Salmonella even when they are fresh

2. A piece of fresh meat can contain microorganisms on the surface

3. Canned products may contain microorganisms

4. Chicken meat may be contaminated with Salmonella

5. Cooked foods are free of microorganisms

6. Fresh vegetables can contain microorganisms

\section{Mean (\%)}

\section{Group 2: Food handling hygiene}

7. Cuts or wounds on hands should be protected with gloves or finger cots

8. Hands should always be washed with soap, water and disinfectant after handling fresh meat

9. After washing, hands should be dried with a kitchen cloth

10. To handle food that is already cooked is not necessary to wash hands

11. After smoking or going to the bathroom is necessary

to disinfect your hands with soap, water and disinfectant

12. If you are wearing gloves you can handle with fresh meat and cooked food simultaneously

13. When leaving the confection area shoes must be changed or wear protective foot

\section{$\operatorname{Mean}(\%)$}

\section{Group 3: Cross Contamination}

14. Food-borne illnesses can result from contamination of cooked food

15. A preparation which involves many manipulation adds risk of contamination

16. Food can be contaminated through contact with other food

17. Countertops and cutting boards may be responsible for the contamination of a food

\section{$\operatorname{Mean}(\%)$}

\section{Group 4: Heat treatment and cooling techniques}

18. A cooked food can be kept below $5^{\circ} \mathrm{C}$ safely

19. A cooked food can be kept above $65^{\circ} \mathrm{C}$ a few hours safely

20. In foods to be eaten cold (salads) is necessary to make their disinfection

21. The majority of foods must be heated to temperatures of $75^{\circ} \mathrm{C}$ or more

22. Microorganisms can grow in foods preserved for a long time at room temperature

23. Food should be cooled to room temperature to be placed in a refrigerator

$$
\text { Mean (\%) }
$$

\section{Group 5: Reduced Temperatures}

24. Freezing kills any bacteria that can cause food-borne illness

25. Food should be thawed at room temperature

26. The bacteria that causes diseases grows well at room temperature

27. The food prepared well in advance and not stored properly can allow multiplication of microorganisms

Correct

n (\%)

Not

I do Not

correct n (\%)

$50(92.6)$

2 (3.7)

2 (3.7)

50 (92.6)

1 (1.9)

3 (5.6)

20 (37.0)

17 (31.5)

17 (31.5)

24 (50.0)

15 (2.8)

12 (22.2)

31 (57.4)

15 (27.8)

8 (14.8)

48 (88.9)

3 (5.6)

3 (5.6)

73.1

14.8

12.1

52 (96.2)

1 (1.9)

1 (1.9)

51 (94.4)

2 (3.7)

1 (1.9)

42 (77.7)

9 (16.7)

3 (5.6)

21 (38.9)

33 (61.1)

$0(0.0)$

53 (98.1)

1 (1.9)

$0(0.0)$

5 (9.3)

48 (88.8)

1 (1.9)

45 (83.3)

4 (7.4)

5 (9.3)

71.2

25,9

2,9

49 (90.7)

2 (3.7)

$3(5.6)$

48 (88.9)

4 (7.4)

53 (98.1)

$0(0)$

2 (3.7)

54 (100)

$0(0)$

1 (1.9)

94.5

2.7

0 (0)

2.8

$30(55.6) \quad 15(27.8) \quad 9(16.7)$

$40(74.1)$

5 (9.3)

9 (16.7)

35 (64.8)

$18(33.3)$

1 (1.9)

$33(61.1)$

$10(18.5)$

$11(20.4)$

$50(92.6)$

$3(5.6)$

1 (1.9)

$27(50.0)$

25 (46.3)

2 (3.7)

63.3

23.4

10.2

25 (46.3)

24 (44.4)

$5(9.3)$

$32(59.3)$

22 (40.7)

0 (0)

50 (92.6)

1(1.9)

$3(5.6)$

51 (94.4)

2 (3.7)

1 (1.9)

73.1

22.6

4.2 
Table 2. Assessment (\%) of food safety self-reported attitudes of food handlers in the one University of Portugal ( $\mathrm{n}=54)$.

\section{Recall the last time}

\begin{tabular}{cc} 
Yes & No \\
\hline $\mathrm{n}(\%)$ & $\mathrm{n}(\%)$
\end{tabular}

Q1. After handling foods on a board. Which he did before preparing other food on the same board?

Washed their hands with soap. water and disinfectant

$41(75.9) \quad 13(24.1)$

Q2. Prepared food in a cutting board. Which did before?

$$
\text { To prepare different food uses different utensils properly disinfected }
$$

Q3. The last time you used a tool like a knife. What did you do before you use this machine to prepare other food?

To prepare different food uses different utensils properly disinfected

Q4. The last time there was leftover food. What you did?

$$
\text { Not keep leftovers }
$$

Q5. After cooking a cold food (salad). What have you made until it was served?

Q6. After confection of hot food. What have you made until it was served?

$$
\text { Puts the food immediately in a water bath }
$$

Table 3. The relationship of food handlers' knowledge level by groups of questions and their socio-demographic characteristics and type of establishment, and knowledge level.

\begin{tabular}{|c|c|c|c|c|c|}
\hline Models & Variable & Wald $\chi^{2}$ & $p$-value & $\begin{array}{l}\text { Adjusted } \\
\text { odds ratio }\end{array}$ & $95 \%$ CI \\
\hline Model 1 & Intercept & 8.147 & 0.004 & 0.333 & - \\
\hline \multirow[b]{2}{*}{$\begin{array}{c}\text { Model 2 } \\
\text { Group 5: Reduced temperatures }\end{array}$} & Intercept & 10.386 & 0.001 & 0.199 & - \\
\hline & Prof. experience & 5.325 & 0.021 & 5.465 & $1.291-23.125$ \\
\hline Model 3 & Intercept & 0.991 & 0.320 & 0.714 & - \\
\hline Total Level of knowledge $(\leq 80 \%,>80 \%)$ & Type of Establishment & 4.267 & 0.039 & 3.640 & $1.068-12.402$ \\
\hline
\end{tabular}

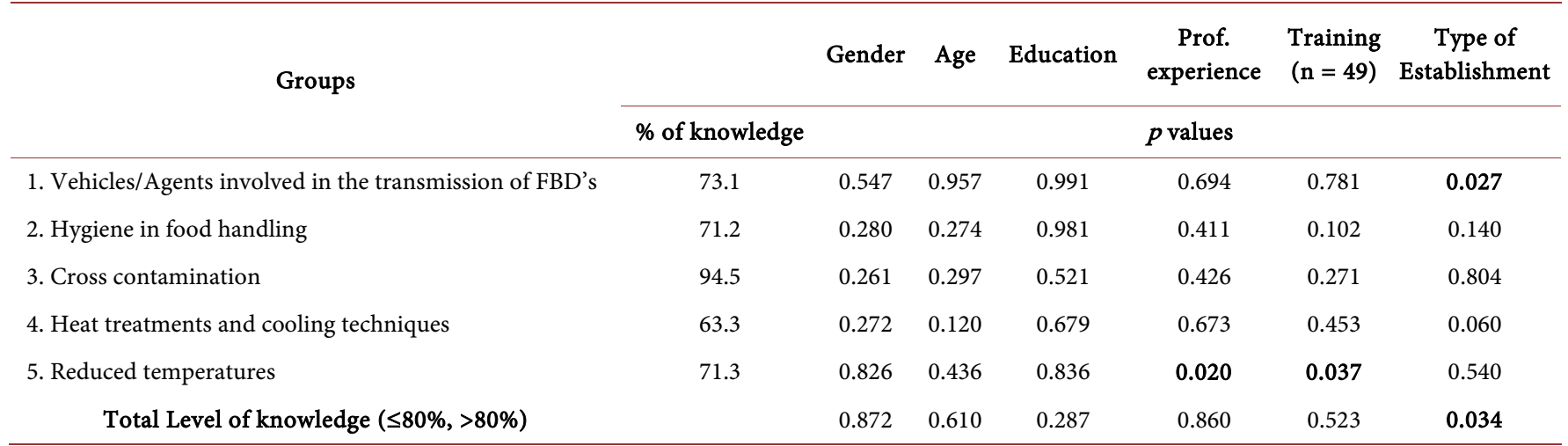

Table 4. Models of logistic regression predicting food handlers' knowledge level for groups 1 and 5, and for total level of knowledge. 
of which reflected higher knowledge had less than two years of training. FH of over 2 years of training just 9 in 35 (25\%) had high knowledge. This factor it is related with another feature analyzed, professional experience, where we find that $\mathrm{FH}$ who worked more than 10 years in area (in the same workplace), only 9 in 36 (25\%) had high knowledge.

Through the model 3, in relation to the significance of type of establishment (Wald $\chi^{2}=4.686, p=0.030$ ), those handlers who worked in cafes have 3.64 times greater likelihood global level of knowledge than those who work in canteens.

Table 5 presents the association between the socio-demographic characteristics of $\mathrm{FH}$ with the average of each question groups and with the average of SRA obtained by the chi-square tests.

In Q3 about the use of different knives for food, significant differences were found for gender $\left(\chi^{2}=5.405, \mathrm{df}=1, p=0.02\right)$ where men responded more correctly than women. Relating to the Q2 of using separate cutting boards for different foods, significant differences were found for age $\left(\chi^{2}=4.378, \mathrm{df}=1, p=0.036\right)$, where youngsters responded with proper attitudes.

In Table 6, analyzing the model 1, the odds of having accurate SRA for proper use of

Table 5. The relationship of food handlers' self-reported attitude level by food safety questions and their socio-demographic characteristics and type of establishment, and total attitude level.

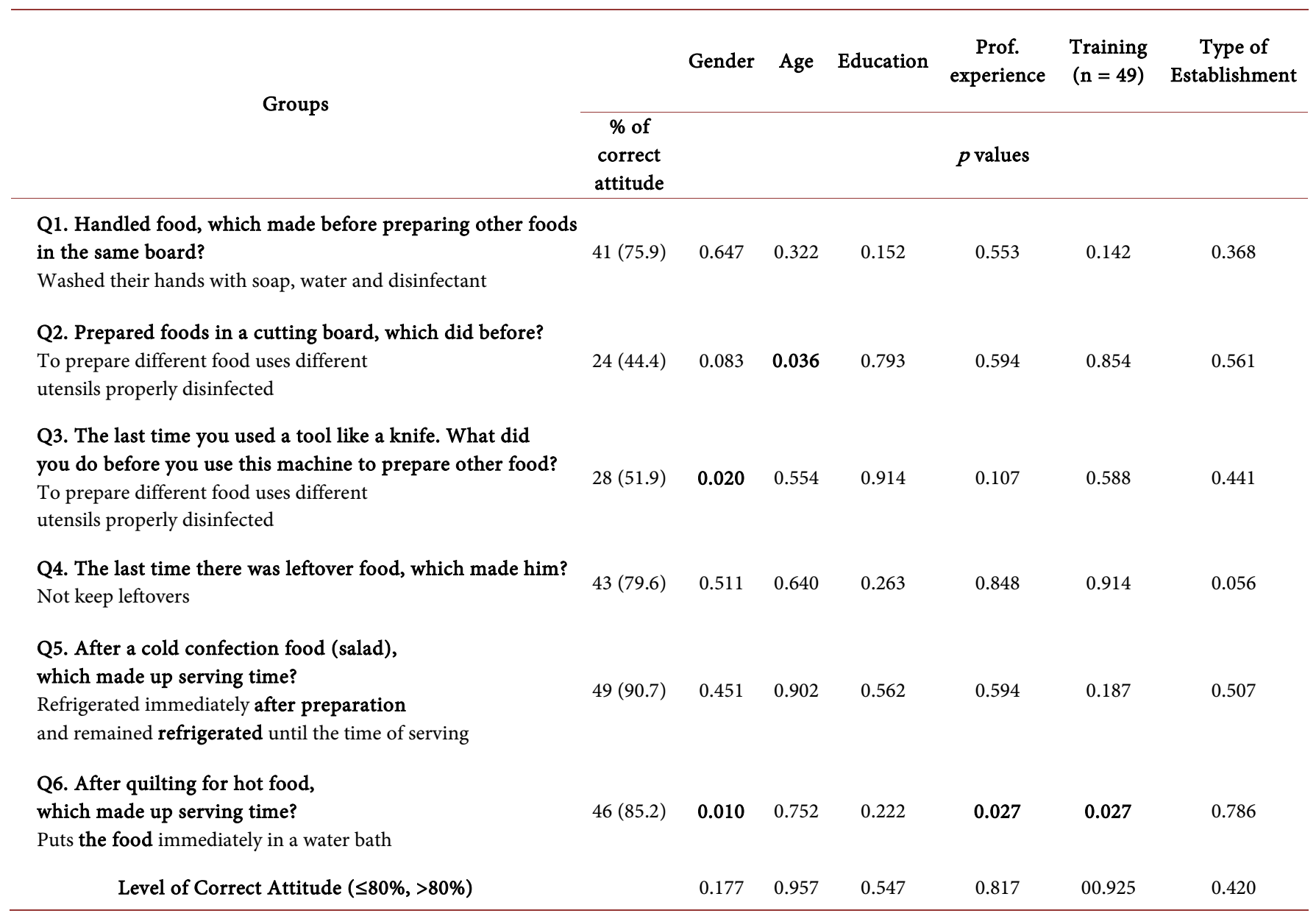


Table 6. Models of logistic regression predicting food handlers' self-reported attitude level for Q2, Q3 and Q6.

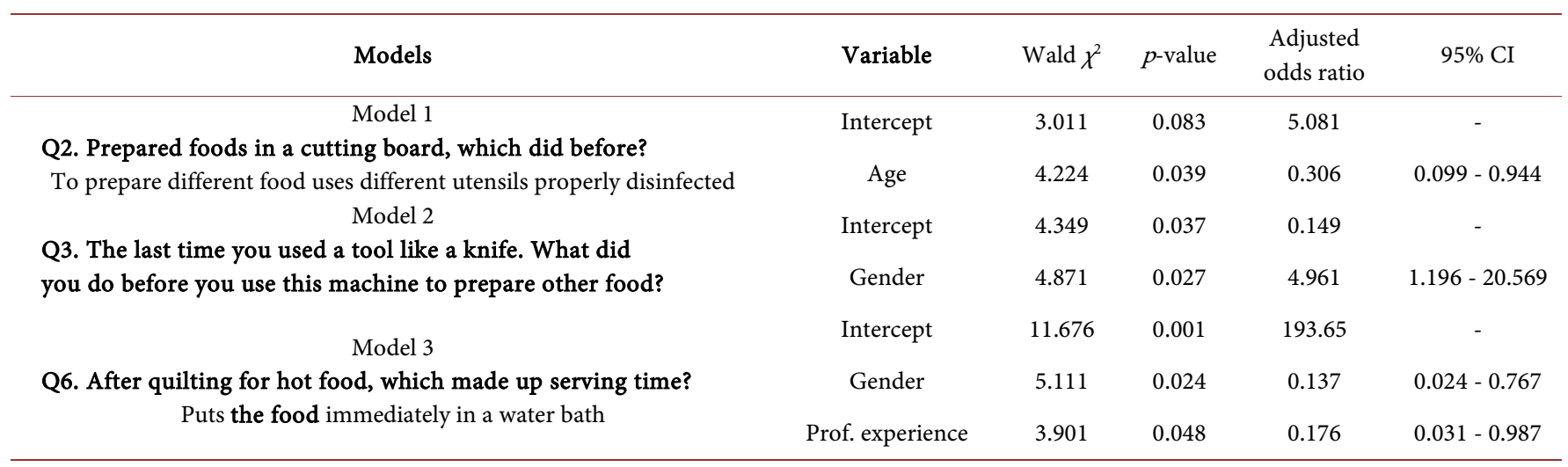

cutting boards are about 0.3 times less on oldest handlers (Wald $\chi^{2}=4.224, p=0.039$ ). In model 2, the odds of having the proper use of knives in different food products were 4.96 times greater in men (Wald $\chi^{2}=4.871, p=0.027$ ). Through the model 3 , notes that in relation to gender, the odds of having a more accurate SRA were 0.14 times lower in women (Wald $\chi^{2}=5.111, p=0.024$ ). Concerning professional experience, the odds of having a more accurate SRA are 0.18 greater in who had more than 10 years of experience towards others (Wald $\chi^{2}=3.901, p=0.048$ ).

\subsection{The Relationship of KL and SRA}

The knowledge variable did not influence the attitude $\left(\chi^{2}=0.894, p=0.344\right)$, as of the 54 handlers, 26 had low knowledge and 28 had high knowledge. But from these $28 \mathrm{FH}$, 16 held improper attitudes. It was also found that the $19 \mathrm{FH}$ who had reduced knowledge and improper attitudes, 4 for in 5didnot have any training in food, and other $\mathrm{FH}$ who had training, still showed deficits in knowledge and attitudes.

\section{Discussion}

In accordance to our data, a report by IP [25] indicates that high percentages of the total workers in this business area are female. Other studies performed in Portugal such as Martins et al. [12], Martins et al. [13] and Santos et al. [14] found more than 96\% FH' female. The latter also found a lower level of education where $74.0 \%$ of FH possessed no more than the 6th grade.

Our study revealed that the level of knowledge that FH on hygiene and food safety was considered good, individually seeing the percentages were above $70 \%$ for issues groups (Table 1) except for G4 issues heat treatment techniques and cooling, which reached only $63.3 \%$ of correct answers. In this group, the incorrect belief that food should be cooled to room temperature and only after placed in refrigeration (Q23) corresponded to $46.3 \%$ of answers, probably due to a common concept of what they do in their houses. Inadequate cooking, improper reheating, high temperatures in freezing and cooling, and cooked food stored for a long time are the main faults detected in this group of poor responses. It is important to highlight the lack of technical knowledge on 
refrigeration storage temperatures (below $\left.5^{\circ} \mathrm{C}\right)$, temperature water bath $\left(65^{\circ} \mathrm{C}\right)$ and domestic food cooking $\left(75^{\circ} \mathrm{C}\right)$.

Training FH to use correctly the temperature is a measure recommended by the $\mathrm{Co}$ dex Alimentarius [24] and should be strengthened by the operator of restaurant units. They are highly important measures in the prevention of food borne illnesses caused by Campylobacter jejuni, Bacillus cereus, Salmonellaspp., Clostridium botulinum, Escherichia coli O157: H7, Yersinia enterolitica and Toxoplasma gondii, among others. In contrast to the known importance of controlling the internal temperature of the food, it was observed that no canteens performed such controls due to the complete lack of thermometers, and also the lack of knowledge about the importance of this control point. Thus, cooking was only controlled by observation and individual culinary experience and sensory evaluation.

An interesting aspect in this research was the discovery that FH working in these university cafes have a higher of global KL $(72 \%)$ than those working in the canteens. The same was observed for G1 answers, showing significant differences of values and higher odds for the cafe handlers' knowledge comparatively to the verified for the canteens' handlers.

The knowledge about G4 were reduced in whom had over 10 years of professional experience and has more than 2 years of training, what can probably be explained by the involvement of the same group of participants. This situation can be related to accommodation aspects of $\mathrm{FH}$ with reducing the importance of certain procedures, perhaps by the fatigue from making the same work for many years and increasing of negligence.

Therefore, it is important to present training alternatives that are not only theoretical knowledge training, but with great practical and participative sessions, such as $O n J o b$ training [26]. This kind of training program allows a greater interaction between participants and the trainer in their workplace and can better assess behaviors and successively carry out the corrections of unjustified actions for food safety and also for the security of the food handler itself.

Individual results of the SRA (Table 2) demonstrated an average score of correct responses that exceeds 70\% for Q1, Q4, Q5 and Q6, and are 44.4\% for Q2 and 51.9\% for Q3. These lower levels of SRA revealed us that even though handlers have a high KL about cross-contamination, verified by $94.5 \%$ of correct answers to G3, they do not apply correctly the procedures of using different tools for different foods. Abdul-Mutalib et al. [17] also referred the importance of using separate kitchen utensils and even though the FH have had training about cross contamination, some of them easily had forgotten about it or just do not pay attention to that fact.

Another important observed aspect, similarly to the one verified by Santos et al. [14], was the absence of measuring the internal temperature of food (Q7), both cafes and canteens, ignore the importance of this procedure. This is probably related to the negligence of those responsible for the establishments, since according CAC [24], the temperature control of foods is a PCC required in HACCP system as it is one of key tools 
in controlling microbial growth. Inadequate temperatures of cooking, cooling, warming and keeping cold or hot until the moment to serve are often the cause of FBD's [12] [27] [28].

Santos et al. [14] showed higher scores (average 95.7\%) of correct attitudes of handlers, unlike our study where only $71.3 \%$ in average of SRA handlers were considered correct, discarding the Q7 related to the usage of thermometer. Lilian et al. [23] found that in the group of attitudes, no handler obtained a score below $50.0 \%$ and the average corresponded to $80.0 \%$ of correct answers. According Baş et al. [10] for the group of questions about attitudes to food safety, the average was $44.2 \%$ and no differences were found between trained and untrained Food handlers $(p>0.05)$. Scores food safety attitudes scores were higher in FH in catering establishments, school food services and hospital food services than in restaurants, hotels, kebab houses and takeaways $(p<$ 0.05).

In our study, no significant difference $(p>0.05)$ was found in SRA scores according to training effect, except for the Q6and type of establishment $\left(\chi^{2}=4.862, p=0.027\right)$. We also observed that no significant associations were observed between attitudes and educational level, mostly due to the inexistence of $\mathrm{FH}$ with low education level (less than 6 years) of education whereas $9.6 \%$ have higher than nine years of school, what can be considered satisfactory for a good learning level.

This study allowed us to find that the FH had a good knowledge and sufficient SRA in relation to food safety and hygiene with the mean score of $75 \%$ and $61.1 \%$, respectively. These findings indicated that although food handlers had good KL they not often applied this while handling foods. However, an association of acquired knowledge in practice is required. For that, it is necessary to maintain the training and supervising as part of an effective strategy to control food safety and hygiene of canteens and cafes.

\section{Conclusions}

This study allows us to analyze the self-reported attitudes and level of knowledge of food handlers, and both parameters are needed for effective management of food safety. Besides the high level of knowledge of food handlers in this study, more than eighty percent of them demonstrate incorrect attitudes.

The professional experience and training time are interrelated. Since the average range for the working time in the ERB is 10 years, we assume that older handlers although they have more training time due to aspects such as age, education level or even the attitude of "I know all" and "make my way", cannot get the most of the given formations, such as those that are less time in the company.

These results justify the implementation of additional measures, including $O n J o b$ training as part of an effective strategy for improving establishment's food safety in view to provide desired attitudes. The implementation of $O n$ Job training is essential as it ensures a style of training not just theoretical in closed room, but in the workplace, where trainer can do corrections of incorrect behavior and attitudes, helping in adequate practices implementation. 
In short, a good education combined with good training, preferably $O n$ Job, can ensure that the handlers to gain awareness and knowledge necessary to meet the requirements of good hygiene practices and manufacturing, while safeguarding their safety and that of consumers.

\section{Acknowledgements}

The authors would like to thank to the respondents for their contributions to this research.

This work is supported by European Investment Funds by FEDER/COMPETE/POCIOperational Competitiveness and Internationalizations Programme, under Project POCI01-0145-FEDER-006958 and National Funds by FCT-Portuguese Foundation for Science and Technology, under the UID/AGR/04033/2013, UID/CVT/00772/2013 and UID/ CVT/00772/2016 projects.

\section{Conflict of Interest}

The authors declare they have no conflict of interest.

\section{References}

[1] Martins, E.A. and Germano, P.M.L. (2008) Microbiological Indicators for the Assessment of Performance in the Hazard Analysis and Critical Control Points (HACCP) System in Meat Lasagna Production. Food Control, 19, 764-771. http://dx.doi.org/10.1016/j.foodcont.2007.08.001

[2] Regulation (EC) 852/2004 (2004) On the Hygiene of Foodstuffs. Official Journal of the European Union, 12, $21 \mathrm{p}$.

[3] Regulation (EC) 853/2004 (2004) Laying down Specific Hygiene Rules for on the Hygiene of Foodstuffs. Official Journal of the European Union, 2, 14 p.

[4] European Food Safety Authority (EFSA) and the European Centre for Disease Prevention and Control (ECDC) (2015) The European Union Summary Report on Trends and Sources of Zoonoses, Zoonotic Agents and Food-Borne Outbreaks in 2013. EFSA Journal, 13, 3991.

[5] Lahou, E., Jacxsens, L., Daelman, J., Van Landeghem, F. and Uyttendaele, M. (2012) Microbiological Performance of a Food Safety Management System in a Food Service Operation. Journal of Food Protection, 75, 706-716.

[6] Isara, A.R., Isah, E.C., Lofor, P.V.O. and Ojide, C.K. (2010) Food Contamination in Fast Food Restaurants in Benin City, Edo State, Nigeria: Implications for Food Hygiene and Safety. Public Health, 124, 467-471. http://dx.doi.org/10.1016/j.puhe.2010.03.028

[7] Zain, N.N. and Naing, N.N. (2002) Sociodemographic Characteristics of Food Handlers and Their Knowledge, Attitude and Practice towards Food Sanitation: A Preliminary Report. The Southeast Asian Journal of Tropical Medicine and Public Health, 33, 410-417.

[8] European Food Safety Authority (EFSA) (2010) The Community Summary Report on Trends and Sources of Zoonoses, Zoonotic Agents and Food-Borne Outbreaks in the European Union in 2008. EFSA Journal, 8, 410-1496.

[9] Jianu, C. and Chiş, C. (2012) Study on the Hygiene Knowledge of Food Handlers Working in Small and Medium-Sized Companies in Western Romania. Food Control, 26, 151-156. http://dx.doi.org/10.1016/j.foodcont.2012.01.023 
[10] Baş, M., Ersun, A.S. and Kivanç, G. (2006) The Evaluation of Food Hygiene Knowledge, Attitudes, and Practices of FH' in Food Businesses in Turkey. Food Control, 17, 317-322. http://dx.doi.org/10.1016/j.foodcont.2004.11.006

[11] Gomes-Neves, E., Araújo, A.C., Ramos, E. and Cardoso, C.S. (2007) Food Handling: Comparative Analysis of General Knowledge and Practice in Three Relevant Groups in Portugal. Food Control, 18, 707-712. http://dx.doi.org/10.1016/j.foodcont.2006.03.005

[12] Martins, R.B., Hogg, T. and Otero, J.G. (2012) Food Handler's Knowledge on Food Hygiene: The Case of a Catering Company in Portugal. Food Control, 27, 206-213.

[13] Martins, R.B., Ferreira, D., Moreira, M.L., Hogg, T. and Gestal, J. (2014) Knowledge on Food Hygiene of Food Service Staff Working in Nursing Homes and Kindergartens in Porto Region-Portugal. Food Control, 42, 54-62. http://dx.doi.org/10.1016/j.foodcont.2014.01.037

[14] Santos, M.J., Nogueira, J.R., Patarata, L. and Mayan, O. (2008) Knowledge Level of Food Handlers in Portuguese School Canteens and Their Self-Reported Behavior towards Food Safety. International Journal of Environmental Health Research, 18, 387-401. http://dx.doi.org/10.1080/09603120802100212

[15] Soares, L.S., Almeida, R.C.C., Cerqueira, E.S., Carvalho, J.S. and Nunes, I.L. (2012) Knowledge, Attitudes and Practices in Food Safety and the Presence of Coagulase-Positive Staphylococci on Hands of Food Handlers in the Schools of Camaçari, Brazil. Food Control, 23,184-190. http://dx.doi.org/10.1016/j.foodcont.2012.03.016

[16] Soares, K. (2013) Avaliação dos conhecimentos e atitudes de manipuladores de alimentos e de parâmetros de higiene em cantinas e bares universitários-Efeito da formação On Job. Dissertação. UTAD, Portugal, 161 p.

[17] Abdul-Mutalib, N.-A., Abdul-Rashid, M.-F., Mustafa, S., Amim-Nordin, S., Hamat, R.A., et al. (2012) Knowledge, Attitude and Practices Regarding Food Hygiene and Sanitation of FH in Kuala Pilah, Malaysia. Food Control, 27, 289-293.

http://dx.doi.org/10.1016/j.foodcont.2012.04.001

[18] Tokuç, B., Ekuklu, G., Berberoglu, U., Bilge, E. and Dedeler, H. (2009) Knowledge, Attitudes and Self-Reported Practice of Food Service Staff Regarding Food Hygiene in Edirne, Turkey. Food Control, 20, 565-568. http://dx.doi.org/10.1016/j.foodcont.2008.08.013

[19] Walker, E., Pritchard, C. and Forsythe, S. (2003) Food Handlers' Hygiene Knowledge in Small Food Businesses. Food Control, 14, 339-343.

http://dx.doi.org/10.1016/S0956-7135(02)00101-9

[20] Soriano, J.M., Rico, H., Moltó, J.C. and Mañes, J. (2002) Effect of Introduction of HACCP on the Microbiological Quality of Some Restaurant Meals. Food Control, 13, 253-261. http://dx.doi.org/10.1016/S0956-7135(02)00023-3

[21] (2006) Decree-Law No. 113/2006. Official Gazette I-Series-A, Portugal.

[22] Santos, M.J. (2006) Segurança Alimentar em cantinas escolares do distrito de Vila Real. Dissertação. FMUP-ICBAS 2006, 120 p.

[23] Lilian, S.S., Rogéria, C.C.A., Ellayne, S.C., Joelza, S.C. and Itaciara, L.N. (2012) Knowledge, Attitudes and Practices in Food Safety and the Presence of Coagulase-Positive Staphylococci on Hands of Food Handlers in the Schools of Camaçari, Brazil. Food Control, 27, 206209. http://dx.doi.org/10.1016/j.foodcont.2012.03.016

[24] Codex Alimentarius Commission (CAC) (2003) Food Hygiene Basic Texts. 3rd Edition, Roma, 68 p.

[25] Instituto para Qualificação na Formação (IP) (2005) O turismo em Portugal. 1a Ed., Mini- 
stério do Trabalho e Solidariedade Social, Lisboa, Portugal, 269 p.

[26] Soares, K., Garcia-Diez, J., Esteves, A., Oliveira, I. and Saraiva, C. (2013) Evaluation of Food Safety Training on Hygienic Conditions in Food Establishments. Food Control, 34, 613618. http://dx.doi.org/10.1016/j.foodcont.2013.06.006

[27] Adams, M.R. and Moss, M.O. (2008) Food Microbiology. 3rd Edition, The Royal Society of Chemistry, Cambridge, 463 p.

[28] Jay, J.M. (2000) Modern Food Microbiology. 6th Edition, Aspen Publishers, Inc., Gaithersburg, 635 p. http://dx.doi.org/10.1007/978-1-4615-4427-2

Submit or recommend next manuscript to SCIRP and we will provide best service for you:

Accepting pre-submission inquiries through Email, Facebook, LinkedIn, Twitter, etc.

A wide selection of journals (inclusive of 9 subjects, more than 200 journals)

Providing 24-hour high-quality service

User-friendly online submission system

Fair and swift peer-review system

Efficient typesetting and proofreading procedure

Display of the result of downloads and visits, as well as the number of cited articles

Maximum dissemination of your research work

Submit your manuscript at: http://papersubmission.scirp.org/

Or contact health@scirp.org 